\title{
Article
}

\section{Association of P10L Polymorphism in Melanopsin Gene with Chronic Insomnia in Mexicans}

\author{
Bianca Ethel Gutiérrez-Amavizca ${ }^{1}$, Ernesto Prado Montes de Oca ${ }^{2,3}$, Jaime Paul Gutiérrez-Amavizca ${ }^{1}$, \\ Oscar David Castro ${ }^{1}$, Cesar Heriberto Ruíz-Marquez ${ }^{1}$, Kricel Perez Conde-Andreu ${ }^{1}$, Ricardo Pérez Calderón ${ }^{4}$, \\ Marisela Aguirre Ramírez ${ }^{1,5}$ and Jorge Alberto Pérez-León 1,5,*(D)
}

1 Chemical Biological Sciences PhD Graduate Program, Department of Chemical Sciences, Biomedical Sciences Institute, Ciudad Juarez Autonomous University, Chihuahua 32310, Mexico; ethe190210@gmail.com (B.E.G.-A.); jaime.gutierrez@uacj.mx (J.P.G.-A.); al114657@alumnos.uacj.mx (O.D.C.); a197587@alumnos.uacj.mx (C.H.R.-M.); kandreu92@gmail.com (K.P.C.-A.); marisela.aguirre@uacj.mx (M.A.R.)

2 Laboratory of Regulatory SNPs and Laboratory of Pharmacogenomics and Preventive Medicine, Personalized Medicine National Laboratory (LAMPER), Pharmaceutical and Medical Biotechnology, Central Unit, CIATEJ, A.C., National Council of Science and Technology (CONACYT), Guadalajara 44270, Mexico; eprado@ciatej.mx or eprado@scripps.edu

3 Scripps Research Translational Institute \& Scripps Integrative Structural and Computational Biology Research Institute La Jolla, La Jolla, CA 92307, USA

4 Genomics Sciences Masters Program, Department of Chemical Sciences, Biomedical Sciences Institute, Ciudad Juarez Autonomous University, Chihuahua 32310, Mexico; al154318@alumnos.uacj.mx

5 Cuerpo Académico Consolidado Biología Celular y Molecular, Instituto de Ciencias Biomédicas, Universidad Autónoma de Ciudad Juárez, Ciudad Juárez, Chihuahua 32310, Mexico

check for updates

Citation: Gutiérrez-Amavizca, B.E.; Prado Montes de Oca, E.; Gutiérrez-Amavizca, J.P.; Castro, O.D.; Ruíz-Marquez, C.H.; Perez Conde-Andreu, K.; Pérez Calderón,

R.; Aguirre Ramírez, M.; Pérez-León, J.A. Association of P10L

Polymorphism in Melanopsin Gene with Chronic Insomnia in Mexicans. Int. J. Environ. Res. Public Health 2021 18, 571. https://doi.org/10.3390/ ijerph18020571

Received: 10 December 2020 Accepted: 2 January 2021 Published: 12 January 2021

Publisher's Note: MDPI stays neutral with regard to jurisdictional clai$\mathrm{ms}$ in published maps and institutional affiliations.

Copyright: (C) 2021 by the authors. Licensee MDPI, Basel, Switzerland. This article is an open access article distributed under the terms and conditions of the Creative Commons Attribution (CC BY) license (https:// creativecommons.org/licenses/by/ $4.0 /)$
* Correspondence: alberto.perez@uacj.mx

Abstract: The aim of this pilot study was to determine the association of the P10L (rs2675703) polymorphism of the OPN4 gene with chronic insomnia in uncertain etiology in a Mexican population. A case control study was performed including 98 healthy subjects and 29 individuals with chronic insomnia not related to mental disorders, medical condition, medication or substance abuse. Samples were genotyped by polymerase chain reaction-restriction fragment length polymorphism (PCR-RFLP). Genetic analyses showed that the T allele of P10L increased risk to chronic insomnia in a dominant model $\left(p=1 \times 10^{-4}\right.$; odds ratio $(\mathrm{OR})=9.37, \mathrm{CI}=8.18-335.66$, Kelsey statistical power $\left.(\mathrm{KSP})=99.9 \%\right)$, and in a recessive model $\left(p=7.5 \times 10^{-5}, \mathrm{OR}=9.37, \mathrm{KSP}=99.3 \%, \mathrm{CI}=2.7-34.29\right)$. In the insomnia group, we did not find a correlation between genotypes and chronotype ( $p=0.219$ Fisher's exact test), severity of chronic insomnia using ISI score ( $p=0.082$ Fisher's exact test) and ESS score $(p>0.999$ Fisher's exact test). However, evening chronotype was correlated to daytime sleepiness severity, individuals with an eveningness chronotype had more severe drowsiness according to their insomnia severity index (ISI) score ( $p=0.021$ Fisher's exact test) and Epworth sleepiness scale (ESS) score ( $p=0.015$ Fisher's exact test) than the morningness and intermediate chronotype. We demonstrated that the T allele of the P10L polymorphism in the OPN4 gene is associated with chronic insomnia in Mexicans. We suggest the need to conduct larger studies in different ethnic populations to test the probable association and function of P10L and other SNPs in the OPN4 gene and in the onset of chronic insomnia.

Keywords: OPN4 gene; melanopsin; insomnia; SNPs; retina; chronotypes

\section{Introduction}

Insomnia is characterized by the difficulty to initiate and/or maintain sleep, which results in either chronically non-restorative or poor quality sleep. It is a serious health problem with a prevalence of $10-50 \%$ in the general population. Patients with insomnia have a positive family history of $\sim 35 \%$ [1]. Many factors are involved in insomnia-environmental as well as genetic - even though these components have not been clearly defined. The 
global literature contains only one case report of a patient with chronic insomnia, which was a heterozygous carrier of nonsense mutation in the GABRB3 gene. This mutation is located in exon six and consists of the substitution of the amino acid arginine with histidine at position 192 (R192H). The patient had a family history of sleep problems [2].

Melanopsin is a photosensitive protein present in a subset of the ganglion cells in the retina of all vertebrates, including humans. The melanopsin-containing cells are known as intrinsically photosensitive retinal ganglion cells (ipPRG). ipPRG act as an additional photoreceptor to the classical rod and cone cells-reviewed in [3]. They directly project into the suprachiasmatic nuclei (SCN), the pacemaker of biological rhythms. Melanopsin mediated phototransduction, performed by the ipRGCs, is complementary to the activity of cones and rods for SCN photosynchronization, but only the ipPRG axons constitute the retinohypothalaic tract that conducts the nerve impulse required for $\mathrm{SCN}$ photosynchronization [3]. It is then understandable that a large number of investigations have focused on the relationship of melanopsin and ipPRG in behavioral disorders of the circadian rhythm-reviewed in [4]). In humans, the participation of melanopsin has already been demonstrated in different behavioral disorders, such as seasonal affective disorder [5] and delayed sleep/wake timing [6] (see below).

There are three isoforms of protein opsin 4 consisting of 478,489 and 495 amino acid residues, they have a molecular weight of 52.6, 53.8 and $54.5 \mathrm{kDa}$ [7]. Opsin 4 is encoded by the OPN4 gene, located on chromosome 10q23.2, with a length of 12,292 bases (Genecards). Functional single nucleotide polymorphisms (SNPs) identified in the OPN4 gene are: P10L (rs2675703), I394T (rs1079610), and D444G (rs12262894). See supplementary Figure S1. The P10L polymorphism is a change from proline to a leucine at position 10, it seems to not interfere with the correct distribution of melanopsin on the plasma membrane. However, SNP P10L has been associated with seasonal affective disorder, a condition where depressive states are experienced in autumn and winter, when days are shorter [8,9]. The I394T polymorphism is a change of isoleucine by tyrosine at position 394 and has been associated with a pupillary light response under various photic conditions including different intensities and wavelengths [10]. The D444G polymorphism consists of the replacement of aspartic acid by glycine at position 444 , it is frequent in African populations $(4.9 \%$, and has been classified as a benign variant with no associated phenotype [11]. These different associations of the OPN4 gene SNPs show how melanopsin mediated photransduction and ipRGCs activity are associated with several light-driven functions not related to vision.

Affective and sleep disorders are related. Correct sleep homeostasis is dependent upon an efficient sensing of environmental light. The P10L SNP associated with affective disorder, could be also linked to a defective sensing of environmental light leading to perturbance in sleep homeostasis, manifesting most severely as difficulty initiating and/or maintaining this process. Hence, we wanted to seek an association between the P10L polymorphism OPN4 gene and insomnia. Thus, the aim of this study was to determine whether there was an association between the OPN4 gene P10L polymorphism and chronic insomnia of uncertain etiology in a Mexican population.

\section{Materials and Methods}

\subsection{Subjects}

We included 98 healthy individuals as a control group. This consisted of individuals who were older than 18 years, who did not have family history or suffer from a primary sleep disorder. The patient group included 29 individuals diagnosed with chronic insomnia of uncertain etiology according to the criteria of the Diagnostic and Statistical Manual of Mental Disorders (DSM-5). Excluding criteria were a history of mental disorder, medical condition, medication or substance abuse. All patients and healthy subjects were provided with written informed consent to participate in this study, in adherence with the Declaration of Helsinki and General Health Law of Mexico that regulates health and research. This study was accepted by the Institutional Committee of Ethics and Bioethics of the University Autonomous of Juarez City (CIBE-2016-1-40). 
The control group participants were required to self-complete a set of questionnaires including clinical sleep characteristics and chronotype evaluation. The Composite Scale of Morningness (CSM) —adapted in Spanish [12]—and the chronic insomnia group participants answered the same questionnaires as the control group, plus the Epworth Sleepiness Scale (ESS), insomnia severity index (ISI) and Pittsburgh scale quality index (PSQI).

\subsection{Instruments}

\subsubsection{Chronotype Evaluation Composite Scale of Morningness (CSM)}

The CSM was used to categorize chronotype in one of three groups: morningness, intermediate and eveningness [13].

\subsubsection{Epworth Sleepiness Scale (ESS)}

The ESS ranks daytime sleepiness into: daytime sleepiness; fair likely daytime sleepiness; highly daytime sleepiness; and excessive daytime sleepiness [14].

\subsubsection{Insomnia Severity Index (ISI)}

The ISI assesses the severity of both nighttime and daytime components of insomnia and grades into: no clinically significant insomnia, moderate clinical insomnia and severe clinical insomnia—see details in references $[15,16]$.

\subsubsection{Pittsburgh Scale Quality Index (PSQI)}

The PSQI evaluates sleep quality and disturbances along the previous month. A score $>5$ suggests poor sleep quality [17].

\subsection{Genotyping}

Venous blood was collected in EDTA tubes and genomic DNA was extracted according to Miller [18]. SNP rs2675703 (P10L) was genotyped using an RFLP-PCR assay modified from [5]. Primer sequences were: forward 3'-AGGAAAGTTGGGAGGCTGAG-5', reverse $3^{\prime}$-GGTCAGGGAAGGCTCTGTG- ${ }^{\prime}$. End-point PCR of $100 \mathrm{ng}$ of genomic DNA was performed with the following conditions: denaturation for $10 \mathrm{~min}$ at $95^{\circ} \mathrm{C}$; followed by 45 cycles of $30 \mathrm{~s}$ at $94^{\circ} \mathrm{C}$ (denaturation), $1 \mathrm{~min}$ at $57^{\circ} \mathrm{C}$ (annealing), and $1 \mathrm{~min}$ at $72{ }^{\circ} \mathrm{C}$ (elongation); a final elongation step of $10 \mathrm{~min}$ at $72{ }^{\circ} \mathrm{C}$. A unique $281 \mathrm{bp}$ amplicon of the OPN4 gene with no primer-dimers or unspecific amplicons was obtained in all assays. The PCR products were digested with an AciI restriction enzyme at $37^{\circ} \mathrm{C}$ for $6 \mathrm{~h}$. The designed assay was possible due to two previous observations: (i) rs2675703 (P10L) is adjacent to a second SNP rs11202106 and recombination between these two markers does not occur $\left(\mathrm{D}^{\prime}=1\right.$ according to LDlink [19] and also suggested by Mexicans in Los Angeles (MXL) subpopulation from 1000 genomes project ( $1 \mathrm{kGP}, \mathrm{C}$ allele frequency of rs2675703 $=0.875$ and $\mathrm{G}$ allele of rs2675703 $=0.867$; (ii) there are six possible haplotypes in the world population (ALL populations from 1kGP) including CG, TA, CA, CC, TG and CC. SNP rs11202106 is biallelic and not triallelic in MXL subpopulation (C allele in rs11202106 does not exist). Thus, the AciI cut haplotype CG (allele C of interest) and does not cut in haplotype TA (allele $\mathrm{T}$ of interest). So, the $\mathrm{T} / \mathrm{T}$ genotype generated a unique undigested 281-bp product, the $\mathrm{C} / \mathrm{T}$ genotype produced three bands of $281 \mathrm{bp}, 161$ and $120 \mathrm{bp}$, and the C/C genotype yielded two fragments of 161 and 120.bp. The digested amplicons were analyzed using electrophoresis in $2 \%$ agarose gels, followed by silver staining.

\subsection{Statistical Analysis}

Allele frequencies were determined by counting, and the distribution of genotypes in both groups was compared using the $\chi^{2}$ test or Fisher's exact test. The Hardy-Weinberg equilibrium was calculated in controls using the $\chi^{2}$ test. Odds ratios (ORs) with $95 \%$ confidence intervals ( $95 \% \mathrm{CIs}$ ) were obtained to estimate the associations between genotypes and disease in a codominant model according to Lewis [20]. A $p$-value of $<0.05$ was considered statistically significant. Kelsey and Fleiss parameters were calculated as 
post hoc statistical powers for each genotype comparison with EpiInfo software (StatCalc, Centers for Diseases Control, Atlanta, GA, USA) v. 7.2.4.0. Two-sided confidence intervals of $95 \%$ was considered in all genetic models.

\section{Results}

\subsection{Clinical Characteristics Related to Sleep}

We attempted this study trying to find an association between the polymorphism P10L of the OPN4 gene and chronic insomnia. Subjects were included in two groups: those with no difficulty initiating or maintaining sleep were considered as healthy (control group, $N=98,56$ men, 42 women) and individuals suffering from chronic insomnia $(N=29$, 20 women, 9 men). The median age in the control group was $23.14 \pm 6.36$ (mean \pm SD) (range 17-61), while in the insomnia group it was $38.62 \pm 13.85$ (mean $\pm \mathrm{SD}$ ) (range 1863). In the insomnia group, an obesity trend was identified, defined as body mass index (BMI) [21] overweight in 44.8\%, BMI between 25-29.9, type 1 obesity BMI between 30-34.9, in $13.8 \%$, and type 2 obesity in $6.9 \%$ (BMI between $35-39.9$ ). Whereas this distribution in the control group was restricted to normal weight $59.6 \%$, overweight $24.6 \%$ and type 1 obesity $9.7 \%$. with no type 2 obesity. These differences were significant (Fisher's exact test, $p<0.012$.

Sleep duration in hours in the insomnia group was $5.41 \pm 1.34$ (mean \pm SD) (range 3-9), however, it must be taken into account that $62 \%$ were taking medication for insomnia. No significant differences were found between groups in the chronotype $(p=0.241)$.

Clinical features, symptoms and behavioral disturbances related to sleep such as apnea, bad quality of sleep, lacking feeling of restful sleep, difficulty in maintaining sleep, difficulty in concentration, alteration in mood, muscular tension, seasonal depression and anxiety were statistically significant, being more prevalent in the insomnia group (Table 1). Patients with chronic insomnia reported poor sleep quality in $62.1 \%$, while in the control group it was only the $11 \%$. However, when sleep quality was measured in diurnal naps no differences were found. A total of $89.7 \%$ of patients with insomnia reported a poor feeling of rest, while in the control group it was $42.2 \%$.

Table 1. Clinical characteristic and behavioral disturbances related to sleep in chronic insomnia patients.

\begin{tabular}{|c|c|c|c|}
\hline Characteristics & Control Group $N=98(\%)$ & Chronic Insomnia Group $N=29(\%)$ & $p$-Value \\
\hline \multicolumn{4}{|l|}{ Apnea } \\
\hline Yes & $9(9.2)$ & $15(51.7)$ & \\
\hline No & $89(90.8)$ & $14(48.3)$ & $<0.001$ \\
\hline \multicolumn{4}{|l|}{ Sleepiness } \\
\hline Yes & $63(70.4)$ & $23(79.3)$ & \\
\hline No & $34(34.6)$ & $6(20.7)$ & 0.364 \\
\hline \multicolumn{4}{|c|}{ Take a nap during day } \\
\hline Yes & $39(39.8)$ & $7(24.1)$ & \\
\hline No & $59(60.2)$ & $22(75.9)$ & 0.186 \\
\hline \multicolumn{4}{|l|}{ Sleep quality } \\
\hline Good & $30(30.6)$ & 0 & \\
\hline Regular & $58(59.2)$ & $7(24.1)$ & \\
\hline Bad & $9(9.2)$ & $18(62.1)$ & $*<0.001$ \\
\hline \multicolumn{4}{|c|}{ Sensation of restful sleep } \\
\hline Yes & $51(52)$ & $3(10.3)$ & \\
\hline No & $40(40.2)$ & $26(89.7)$ & * 0.001 \\
\hline \multicolumn{4}{|l|}{ Somnambulism } \\
\hline Yes & $10(10.2)$ & $3(10.3)$ & \\
\hline No & $87(88.8)$ & $26(89.7)$ & $>0.999$ \\
\hline \multicolumn{4}{|l|}{ Night terrors } \\
\hline Yes & $13(12.9)$ & $2(6.9)$ & \\
\hline No & $83(83.6)$ & $27(93.1)$ & 0.713 \\
\hline
\end{tabular}


Table 1. Cont.

\begin{tabular}{|c|c|c|c|}
\hline Characteristics & Control Group $N=98(\%)$ & Chronic Insomnia Group $N=29(\%)$ & $p$-Value \\
\hline \multicolumn{4}{|l|}{ Nightmares } \\
\hline Yes & $30(30.6)$ & $11(37.9)$ & \\
\hline No & $68(69.4)$ & $18(62.1)$ & 0.501 \\
\hline \multicolumn{4}{|c|}{ Difficulty maintaining sleep } \\
\hline Yes & $22(22.4)$ & $25(86.2)$ & \\
\hline No & 76 (77.6) & $4(13.8)$ & $*<0.001$ \\
\hline \multicolumn{4}{|l|}{ Fatigue } \\
\hline Yes & $70(71.4)$ & $25(86.2)$ & \\
\hline No & $28(28.6)$ & $4(13.8)$ & *0.145 \\
\hline \multicolumn{4}{|l|}{$\begin{array}{l}\text { Bad performance } \\
\text { school/work }\end{array}$} \\
\hline Yes & $44(44.9)$ & $17(58.6)$ & \\
\hline No & $54(55.1)$ & $12(41.4)$ & 0.211 \\
\hline \multicolumn{4}{|c|}{ Difficulty concentrating } \\
\hline Yes & $50(51.0)$ & $22(75.9)$ & \\
\hline No & $47(48.0)$ & $7(24.1)$ & 0.036 \\
\hline \multicolumn{4}{|c|}{ Difficulty memorizing } \\
\hline Yes & $39(39.8)$ & $16(55.2)$ & \\
\hline No & $59(60.2)$ & $13(44.8)$ & 0.200 \\
\hline \multicolumn{4}{|l|}{ Mood alteration } \\
\hline Yes & $34(34.7)$ & $24(82.8)$ & \\
\hline No & $62(63.3)$ & $5(17.2)$ & 0.002 \\
\hline \multicolumn{4}{|l|}{ Muscular tension } \\
\hline Yes & $44(44.9)$ & $21(72.4)$ & \\
\hline No & $53(541)$ & $8(27.6)$ & 0.016 \\
\hline \multicolumn{4}{|l|}{ Headache } \\
\hline Yes & $33(33.7)$ & $15(51.7)$ & \\
\hline $\mathrm{No}$ & $64(34.7)$ & $14(48.3)$ & 0.184 \\
\hline \multicolumn{4}{|l|}{ Seasonal depression } \\
\hline Yes & $14(14.3)$ & $16(55.2)$ & \\
\hline No & $83(84.7)$ & $13(44.8)$ & 0.001 \\
\hline \multicolumn{4}{|l|}{ Anxiety } \\
\hline Yes & $39(39.8)$ & $22(75.9)$ & \\
\hline No & $59(60.2)$ & $7(24.1)$ & 0.001 \\
\hline
\end{tabular}

$\chi^{2}$ test, significative $p$-value $<0.05,{ }^{*}$ Fisher's test when expected cell is less than 5 .

Family history of at least one member with insomnia in individuals with chronic insomnia was found in $58.6 \%$. Moderate clinical insomnia according to the severity index was found in $37.9 \%$ of individuals and in $24.1 \%$ this was clinically severe. According to Pittsburgh scale, all individuals $(100 \%)$ with insomnia were bad sleepers. Age of onset of symptoms in chronic insomnia individuals was $26.86 \pm 14.51$ (range 10-60). Conforming to EPS, individuals were distributed according to classification: unlikely (51.7\%), fairly likely (13.8\%) highly likely (13.8\%) and excessively likely (20.7\%).

\subsection{Genotyping, Allelic Frequencies and Correlation to Sleep}

Genotype and allele frequencies of the rs2675703 (P10L) polymorphism of the OPN4 gene are shown in Table 2. There is a strong association between the occurrence of the OPN4 gene P10L SNP and insomnia, genotype distributions in the control group were in agreement with the Hardy-Weinberg equilibrium. In the chronic insomnia group, we did not find a correlation between the genotype and chronotype $(p=0.219$ Fisher's exact test), daytime sleepiness severity using ISI score ( $p=0.082$ Fisher's exact test) or ESS score ( $p \geq 0.999$ Fisher's exact test), but when we analyzed the correlation between chronotype with daytime sleepiness severity we found that individuals with an eveningness chronotype had more severe drowsiness according to ISI score ( $p=0.021$ Fisher's exact test) and ESS score ( $p=0.015$ Fisher's exact test) than the morningness and intermediate chronotype (Table 3). 
Table 2. Genotype and allelic frequencies of OPN4 in chronic insomnia.

\begin{tabular}{|c|c|c|c|c|c|}
\hline \multirow{2}{*}{ Genotype } & \multirow{2}{*}{ Controls } & \multirow{2}{*}{ Insomnia Patients } & \multirow{2}{*}{$p$-Value, OR (95\% CI) } & \multicolumn{2}{|c|}{ Statistical Power } \\
\hline & & & & (Kelsey) & (Fleiss) \\
\hline & $N=98(\%)$ & $N=29(\%)$ & & & \\
\hline $\mathrm{C} / \mathrm{C}$ & 72(79.6) & $2(6.9)$ & & & \\
\hline $\mathrm{C} / \mathrm{T}$ & $20(20.4)$ & $16(55.2)$ & & & \\
\hline $\mathrm{T} / \mathrm{T}$ & $6(7.0)$ & 11(37.9) & & & \\
\hline \multicolumn{6}{|l|}{ Model } \\
\hline \multicolumn{6}{|l|}{ Dominant } \\
\hline $\mathrm{TT}+\mathrm{CT}$ & 26 & 27 & & & \\
\hline $\mathrm{CC}$ & 72 & 2 & $p=1 \times 10^{-4}, 37.38(8.18-335.66)$ & $99.9995 \%$ & $99.99999999985 \%$ \\
\hline \multicolumn{6}{|l|}{ Recessive } \\
\hline $\mathrm{TT}$ & 6 & 11 & & & \\
\hline $\mathrm{CC}+\mathrm{CT}$ & 92 & 18 & $p=7.5 \times 10^{-5}, 9.37(2.70-34.29)$ & $99.3 \%$ & $97.0 \%$ \\
\hline \multicolumn{6}{|l|}{ Codominant } \\
\hline $\mathrm{CT}$ & 20 & 16 & & & \\
\hline $\mathrm{CC}+\mathrm{TT}$ & 78 & 13 & $p=7.12 \times 10^{-4}, 4.8(1.8-12.71)$ & $95.4 \%$ & $94.3 \%$ \\
\hline \multicolumn{6}{|l|}{ Allele } \\
\hline C & 164 & 20 & & & \\
\hline $\mathrm{T}$ & 32 & 38 & $p=0.0001,9.73(4.78-19.93)$ & $99.94 \%$ & $99.93 \%$ \\
\hline
\end{tabular}

Table 3. Correlation between chronotype and insomnia severity according to insomnia severity index (ISI) and Epworth Sleepiness Score (ESS).

\begin{tabular}{|c|c|c|c|c|c|c|}
\hline \multirow[t]{2}{*}{ Chronotype } & \multicolumn{2}{|c|}{ ISI Score } & \multirow[t]{2}{*}{$p$-Value } & \multicolumn{2}{|c|}{ ESS Score } & \multirow[t]{2}{*}{$p$-Value } \\
\hline & Subclinical & Moderate-Severe & & Unlikely Sleepiness & Likely Sleepiness & \\
\hline Morningness & $5(50 \%)$ & $2(50 \%)$ & & $6(85.7 \%)$ & $1(14.3 \%)$ & \\
\hline Intermediate & $5(15.4 \%)$ & $6(84.6 \%)$ & & $9(81.8 \%)$ & & \\
\hline Eveningness & $1(60 \%)$ & $10(40 \%)$ & 0.021 & $3(27.3 \%)$ & $8(72.7 \%)$ & 0.015 \\
\hline \multicolumn{3}{|c|}{ Fisher's exact test } & & & Fisher's exact test & \\
\hline
\end{tabular}

\section{Discussion}

Chronic insomnia is the most common primary sleep disorder in the population. Among the risk factors are advanced age, female sex, stress, substance abuse, as well as medical and psychiatric illnesses. There are few genetic studies regarding genetic variations involved in the susceptibility to insomnia. Genetic information can contribute to our understanding of its pathophysiology, the screening of risk factors and the development of an effective treatment. The participation of the ipPRG in the regulation of the sleep wake cycle and therefore the participation of the OPN4 in the integrity of this cycle is evident. Table 4 shows a brief summary of studies reported to date on the genetic contribution of OPN4 gene polymorphisms to sleep and their disturbances which corroborate the implication of melanopsin in the regulation of the photo response, chronotype and sleep cycles. Noteworthy, one study was performed in a Japanese population and two more performed in Caucasian populations, thus, our study is the first report analyzing OPN4 SNPs in a Hispanic/Latin American population sample.

Table 4. Genetic contribution to P10L polymorphism melanopsin gene.

\begin{tabular}{|c|c|c|c|c|c|c|}
\hline Polymorphism & Characteristic & $N$ & OR $(95 \% \mathrm{CI}) / \mathrm{F}$ Test & $p$-Value & Population & Reference \\
\hline \multirow{4}{*}{$\begin{array}{c}\text { P10L } \\
\text { rs2675703 } \\
\text { c.29C>T } \\
\text { Pro10Leu }\end{array}$} & $\begin{array}{l}\text { Seasonal affective } \\
\text { disorder (SAD) }\end{array}$ & $\begin{array}{l}130 \text { SAD } \\
90 \text { control }\end{array}$ & $5.63(1.22-26.01)$ & $<0.05$ & 95\% Non-hispanic Caucasic & Roecklein et al., 2009 \\
\hline & $\begin{array}{l}\text { Sleep onset } \\
\text { Chronotype }\end{array}$ & $\begin{array}{l}234 \text { healthy } \\
\text { individuals }\end{array}$ & $\begin{array}{l}\mathrm{F}(9230)=2.469 \\
\mathrm{~F}(2229)=3.214\end{array}$ & $\begin{array}{l}<0.05 \\
<0.05\end{array}$ & Non-Hispanic Caucasic & Roecklein et al., 2012 \\
\hline & $\begin{array}{c}\text { Bed time } \\
\text { Awakening time }\end{array}$ & $\begin{array}{l}348 \text { healthy } \\
\text { individuals }\end{array}$ & $\begin{array}{l}F=7.058 \\
F=3.353\end{array}$ & $\begin{array}{l}<0.01 \\
<0.05\end{array}$ & Japanese & Lee et al., 2014 \\
\hline & Chronic insomnia & $\begin{array}{c}98 \text { controls } \\
29 \text { chronic insomnia }\end{array}$ & $37.38(8.18-335.66)$ & $<0.01$ & Mexican & This study \\
\hline
\end{tabular}


We found no differences between chronotypes of patients when compared with chronotypes of controls. To our knowledge, no previous study has attempted to sort patients suffering with chronic insomnia into chronotypes, namely, whether individuals could be classified as morning (morningness), intermediate, or evening (eveningness) types. As surprising as this is, for us, the results of particular noteworthiness-regardless of the difficulty to initiate/maintain the sleep-individuals still show a diurnal preference similar to control group.

We demonstrated several statistically different behavioral disturbances in the insomnia group when compared with the control group. From Table 1, the data evidently show that insomnia patients are more susceptible to apnea, bad quality of sleep, lack the feeling of having a restful sleep, difficulty in concentration, alteration in mood, muscular tension, seasonal depression and anxiety. In this way, our analysis reports additional features that lead to a lower quality of life in insomnia patients.

Furthermore, we also detected a trend for the insomnia group to present overweight and obesity: almost one half of the patients showed overweight (44.8\%), and considering both type 1 and type 2 altogether, 20.7\% of individuals were obese $(13.8 \%$ and $6.9 \%$, respectively). That makes a total proportion of more than $65 \%$ patients of chronic insomnia suffering some metabolic disfunction. According to this, it has been demonstrated that the insomnia phenotype is associated with a significant risk of cardiometabolic and neurocognitive morbidity and mortality [22]. Additionally, several studies have demonstrated a strong association between persistent complaints of difficulty initiating or maintaining sleep with an increased risk of hypertension [23], acute myocardial infarction [24] and type 2 diabetes [25].

We performed the genotyping of control and insomnia subjects seeking for the occurrence of OPN4 alleles variants. Our analysis regarding alleles and genotypes strongly reveals a higher risk of insomnia when the $\mathrm{T}$ allele is present in all the genetic models tested. The contribution of allele $\mathrm{T}$ was statistically significant $(p \leq 0.001, \mathrm{OR}=9.73$, $C I=4.78-19.93)$, suggesting an almost ten-fold risk of occurrence of insomnia in individuals with the $\mathrm{T}$ allele. Therefore, the $\mathrm{T}$ allele is a risk factor for chronic insomnia, based on all three inherited models including dominant $(p \leq 0.001, \mathrm{OR}=37.38, \mathrm{CI}=8.18-335.66)$, recessive $\left(p=7.5 \times 10^{-5}, \mathrm{OR}=9.37 \mathrm{CI}=2.70-34.29\right)$ and codominant $\left(p=7.12 \times 10^{-4}\right.$, $\mathrm{OR}=4.8, \mathrm{CI}=1.8-12.71)$. It is important to highlight that when the genotype TT is present, this conveys a risk of being 37.38 times more likely to suffer from chronic insomnia.

Additionally, there is no correlation between genotypes with chronotype and daytime sleepness severity, but interestingly, the chronotype was correlated with daytime sleepiness severity. Individuals with an eveningness chronotype had worse prognosis in terms of severity and sleepiness during the day than those with a morning or intermediate chronotype. Is well known that an evening chronotype carries negative consequences for sleep and reports of higher levels of daytime sleepiness [26] and more maladaptive beliefs about sleep compared to morning types [27]. We found that the chronic insomnia group has $>68 \%$ more patients with the eveningness chronotype than controls. It is probable that the chronotype shift towards eveningness could be a pre-insomnia state, if insomnia is seen as a threshold disease. If this is true, this result would lead to an opportunity to prevent insomnia cases in future approaches. However, this remains to be demonstrated in a longitudinal and larger study. We demonstrated that in all the genotype and allele comparisons the statistical power was above $94.3 \%$, in spite of a low sample size. The high statistical power in our result can be explained due to (i) the marked differences in allele and genotype frequencies (exposures) between cases and controls and to (ii) and the high control/case ratio (3.38).

Evening chronotype has also been associated with clinical depression [28,29], psychopathology in adolescents [30], bipolar disorder [31], subclinical mania [32], and insomnia [33]. Taken together, these studies and ours suggest that poor sleep and eveningness could be a predictive marker of insomnia severity. Therefore, insomnia patients with an evening 
chronotype are particularly high-risk group for sleepiness severity and susceptibility of other mental disorders.

A similar association of this SNP has been found for patients suffering with seasonal affective disorder [5], and also for healthy individuals in predicting their sleep timing and chronotype: earlier bedtimes in shorter days and later bedtimes in longer days [6]. There is no correlation so far between the substitution of proline 10 by leucine in the melanopsin protein and the alteration of its function, even more, it seems that the peptide with the substitution has normal sorting to the plasma membrane [6]. It is therefore difficult to hypothesize on a feasible role for this allele variation leading to a disturbance in light perception and thus in the etiology of insomnia, joined to the fact that P10L did not show melanopsin loss-of function in vitro, with no evidence of protein misfolding in cellular localization. The only reported effect is that cells expressing P10L showed a reduced amplitude response compared with the wild type [34]. Proline to leucine mutations in transmembrane proteins can lead to altered chaperone-mediated stabilization and proteasome-dependent degradation in the central nervous system [35]. Another probable explanation is that P10L could be in linkage with a functional variant. In this regard, additional in silico evidence suggests that P10L SNP (rs2675703) is in complete linkage with the intron SNP rs2254051, having both the same population frequency of $12.5 \%$, as is expected according to $1 \mathrm{kGP}$ in Mexicans in the Los Angeles population. However, SNP rs2254051 has no predicted functional effect nor does it overlap with any regulatory features (See Supplementary Figure S1, [36])

Regardless of the extensively documented role of melanopsin and ipPRG with photoentrainment, there are no studies on the association of the P10L melanopsin SNP with sleep disorders, beyond Seasonal affective disorder (SAD), sleep/awakening time and chronotype reported by Rocklein et al., [5,37] and Lee et al. [6]. Hence, we do not have a source of comparison for our data, nevertheless, it is clear that we have identified an association for P10L with insomnia. Our results suggest that melanopsin is involved in sleep disorders, at least in chronic insomnia. We encourage research groups to conduct larger studies in populations with different ethnic backgrounds in order to reinforce this hypothesis.

\section{Conclusions}

Melanopsin and ipPRG have a primary role in non-visual retinal light responses. Thus, an alteration of melanopsin signaling or ipPRG signaling to encephalic nuclei could also lead to disturbances in sleep control. Several single nucleotide polymorphisms have been reported for the OPN4 gene, and some of these have been related to alterations in extravisual light responses. We analyzed—by genotyping—a group of insomnia patients to look for an association of the P10L polymorphism OPN4 gene. We found a higher risk of suffering with insomnia to be associated with the occurrence of this allele variant. Our preliminary results add evidence to the role of melanopsin and ipPRG in the control of light driven behaviors involved in the sleep-awake cycle, but further research is needed to demonstrate the biological impact of this SNP or its associated functional variant.

Supplementary Materials: The following are available online at https: / www.mdpi.com/1660-4 601/18/2/571/s1, Figure S1: Sequence of isoform 1 of melanopsin protein (478 residues, 10 exons). Missense variants are depicted in yellow. Synonymous variants are depicted in green. Different exons are represented with alternate black and blue residues. Red residues are overlapping splicing sites. Figure was made by the authors using the sequences of OPN4 reported in [34]

Author Contributions: Conceptualization, B.E.G.-A. and J.A.P.-L.; data curation, B.E.G.-A.; formal analysis, B.E.G.-A., E.P.M.d.O., J.P.G.-A. and J.A.P.-L.; funding acquisition, M.A.R. and J.A.P.-L.; investigation, B.E.G.-A., J.P.G.-A., O.D.C., C.H.R.-M., K.P.C.-A., R.P.C. and J.A.P.-L.; project administration, J.A.P.-L.; resources, M.A.R. and J.A.P.-L.; supervision, B.E.G.-A., M.A.R. and J.A.P.-L.; visualization, E.P.M.d.O.; writing—original draft, B.E.G.-A., E.P.M.d.O., J.P.G.-A. and J.A.P.-L.; writing-review and editing, B.E.G.-A., E.P.M.d.O., J.P.G.-A., O.D.C., C.H.R.-M., K.P.C.-A., R.P.C., M.A.R. and J.A.P.-L. All authors have read and agreed to the published version of the manuscript. 
Funding: Bianca Ethel Gutiérrez-Amavizca was a recipient of a postdoctoral scholarship from the National Council of Science and Technology (CONACYT). Jorge Pérez-León received financial support from Programa al Desarrollo Profesional Docente-SEP-2019.

Institutional Review Board Statement: The study was conducted according to the guidelines of the Declaration of Helsinski and approved by the Institutional Committee of Ethics and Bioethics of the University Autonomous of Juarez City (CIBE-2016-1-40) September 2016.

Informed Consent Statement: Informed consent was obtained from all subjects involved in the study.

Data Availability Statement: The data presented in this study are available on request from the corresponding author.

Acknowledgments: Administrative support from Academic Development Coordination (CADAC) of Biomedical Sciences Institute of Autonomous University of Ciudad Juárez is acknowledged.

Conflicts of Interest: We declare that the authors have no conflict of interests that might be perceived to influence the results and/or discussion reported in this paper.

\section{References}

1. Bidaki, R.; Zarei, M.; Toosi, A.K.; Shooshtari, M.H. A review on genetics of sleep disorders. Iran. J. Psychiatry Behav. Sci. 2012, 6, 12-19. [PubMed]

2. Buhr, A.; Bianchi, M.T.; Baur, R.; Courtet, P.; Pignay, V.; Boulenger, J.P.; Gallati, S.; Hinkle, D.J.; Macdonald, R.L.; Sigel, E. Functional characterization of the new human GABAA receptor mutation $\beta 3(\mathrm{R} 192 \mathrm{H})$. Qual. Life Res. 2002, 111, 154-160. [CrossRef] [PubMed]

3. Hughes, S.; Jagannath, A.; Rodgers, J.; Hankins, M.W.; Peirson, S.N.; Foster, R.G. Signalling by melanopsin (OPN4) expressing photosensitive retinal ganglion cells. Eye 2016, 30, 247-254. [CrossRef]

4. Lucas, R.J.; Peirson, S.N.; Berson, D.M.; Brown, T.M.; Cooper, H.M.; Czeisler, C.A.; Figueiro, M.G.; Gamlin, P.D.; Lockley, S.W.; O'Hagan, J.B.; et al. Measuring and using light in the melanopsin age. Trends Neurosci. 2014, 37, 1-9. [CrossRef] [PubMed]

5. Roecklein, K.A.; Wong, P.M.; Miller, M.A.; Donofry, S.D.; Kamarck, M.L.; Brainard, G.C. Melanopsin, photosensitive ganglion cells, and seasonal affective disorder. Neurosci. Biobehav. Rev. 2013, 37, 229-239. [CrossRef]

6. Lee, S.-I.; Hida, A.; Kitamura, S.; Mishima, K.; Higuchi, S. Association between the melanopsin gene polymorphism OPN4*Ile394Thr and sleep/wake timing in Japanese university students. J. Physiol. Anthropol. 2014, 33, 9. [CrossRef]

7. The Human Protein Atlas. Available online: https:/ /www.proteinatlas.org/ (accessed on 4 March 2020).

8. Roecklein, K.A.; Rohan, K.J.; Duncan, W.C.; Rollag, M.D.; Rosenthal, N.E.; Lipsky, R.H.; Provencio, I. A missense variant (P10L) of the melanopsin (OPN4) gene in seasonal affective disorder. J. Affect. Disord. 2009, 114, 279-285. [CrossRef]

9. Roecklein, K.; Wong, P.; Ernecoff, N.; Miller, M.; Donofry, S.; Kamarck, M.; Wood-Vasey, W.M.; Franzen, P. The post illumination pupil response is reduced in seasonal affective disorder. Psychiatry Res. 2013, 210, 150-158. [CrossRef]

10. Lee, S.-I.; Hida, A.; Tsujimura, S.-I.; Morita, T.; Mishima, K.; Higuchi, S. Association between melanopsin gene polymorphism (I394T) and pupillary light reflex is dependent on light wavelength. J. Physiol. Anthropol. 2013, 32, 16. [CrossRef]

11. Clinvar for Gene Symbols. Available online: https:/ / www.ncbi.nlm.nih.gov/clinvar (accessed on 4 March 2020).

12. Díaz-Morales, J.F.; Sánchez-López, M.P. Composite and Preferences scales of morningness: Reliability and factor invariance in adult and university samples. Span. J. Psychol. 2004, 7, 93-100. [CrossRef]

13. Smith, C.S.; Reilly, C.; Midkiff, K. Evaluation of three circadian rhythm questionnaires with suggestions for an improved measure of morningness. J. Appl. Psychol. 1989, 74, 728-738. [CrossRef] [PubMed]

14. Johns, M.W. A new method for measuring daytime sleepiness: The epworth sleepiness scale. Sleep 1991, 14, 540-545. [CrossRef] [PubMed]

15. Morin, C.M. Insomnia: Psychological Assessment and Management; Guilford Press: New York, NY, USA, 1993.

16. Bastien, C.H.; Vallieres, A.; Morin, C.M. Validation of the Insomnia Severity Index as an outcome measure for insomnia research. Sleep Med. 2001, 2, 297-307. [CrossRef]

17. Buysse, D.J.; Reynolds, C.F.; Monk, T.H.; Berman, S.R.; Kupfer, D.J. The Pittsburgh sleep quality index: A new instrument for psychiatric practice and research. Psychiatry Res. 1989, 28, 193-213. [CrossRef]

18. Miller, S.A.; Dykes, D.D.; Polesky, H.F. A simple salting out procedure for extracting DNA from human nucleated cells. Nucleic Acids Res. 1988, 16, 1215. [CrossRef]

19. LDlink Suite Web-Based Applications to Interrogate Linkage in Population Groups. Available online: https://ldlink.nci.nih.gov/ (accessed on 4 March 2020).

20. Lewis, C. Genetic association studies: Design, analysis and interpretation. Brief. Bioinform. 2002, 3, 146-153. [CrossRef]

21. Weir, C.B.; Jan, A. BMI Classification Percentile and Cut off Points. Available online: https://www.statpearls.com/ArticleLibrary/ viewarticle/35288 (accessed on 29 December 2020).

22. Fernandez-Mendoza, J.; Vgontzas, A.N. Insomnia and its impact on physical and mental health. Curr. Psychiatry Rep. 2013, 15, 1-8. [CrossRef] 
23. Suka, M.; Yoshida, K.; Sugimori, H. Persistent insomnia is a predictor of hypertension in Japanese male workers. J. Occup. Health 2003, 45, 344-350. [CrossRef]

24. Laugsand, L.E.; Vatten, L.J.; Platou, C.; Janszky, I. Insomnia and the risk of acute myocardial infarction: A population study. Circulation 2011, 124, 2073. [CrossRef]

25. Kawakami, N.; Takatsuka, N.; Shimizu, H. Sleep disturbance and onset of type 2 diabetes. Diabetes Care 2004, $27,282-283$. [CrossRef]

26. Carrier, J.; Monk, T.H.; Buysse, D.J.; Kupfer, D.J. Sleep and morningness-eveningness in the 'middle' years of life (20-59 y). J. Sleep Res. 1997, 6, 230-237. [CrossRef] [PubMed]

27. Adan, A.; Fabbri, M.; Natale, V.; Prat, G. Sleep Beliefs Scale (SBS) and circadian typology. J. Sleep Res. 2006, 15, 125-132. [CrossRef] [PubMed]

28. Gaspar-Barba, E.; Calati, R.; Cruz-Fuentes, C.S.; Ontiveros-Uribe, M.P.; Natale, V.; de Ronchi, D.; Serretti, A. Depressive symptomatology is influenced by chronotypes. J. Affect. Disord. 2009, 119, 100-106. [CrossRef] [PubMed]

29. Hasler, B.P.; Allen, J.J.B.; Sbarra, D.A.; Bootzin, R.R.; Bernert, R.A. Morningness-eveningness and depression: Preliminary evidence for the role of the behavioral activation system and positive affect. Psychiatry Res. 2010, 176, 166-173. [CrossRef] [PubMed]

30. Li, S.X.; Chan, N.Y.; Yu, M.W.M.; Lam, S.P.; Zhang, J.; Chan, J.W.Y.; Li, A.M.; Wing, Y.K. Eveningness chronotype, insomnia symptoms, and emotional and behavioural problems in adolescents. Sleep Med. 2018, 47, 93-99. [CrossRef] [PubMed]

31. Mansour, H.A.; Wood, J.; Chowdari, K.V.; Dayal, M.; Thase, M.E.; Kupfer, D.J.; Monk, T.H.; Devlin, B.; Nimgaonkar, V.L. Circadian phase variation in bipolar I disorder. Chronobiol. Int. 2005, 22, 571. [CrossRef] [PubMed]

32. Soehner, A.M.; Kennedy, K.S.; Monk, T.H. Personality correlates with sleep-wake variables. Chrono Int. 2007, 24, 889-903. [CrossRef]

33. Ong, J.C.; Huang, J.S.; Kuo, T.F.; Manber, R. Characteristics of insomniacs with self-reported morning and evening chrono-types. J. Clin. Sleep Med. 2007, 3, 289-294. [CrossRef]

34. Rodgers, J.; Peirson, S.N.; Hughes, S.; Hankins, M.W. Functional characterisation of naturally occurring mutations in human melanopsin. Cell. Mol. Life Sci. 2018, 75, 3609-3624. [CrossRef]

35. Gunawardana, C.G.; Mehrabian, M.; Wang, X.; Mueller, I.; Lubambo, I.B.; Jonkman, J.E.N.; Wang, H.; Schmitt-Ulms, G. The human tau interactome: Binding to the ribonucleoproteome, and impaired binding of the proline-to-leucine mutant at position 301 (P301L) to chaperones and the proteasome. Mol. Cell. Proteom. 2015, 14, 3000-3014. [CrossRef]

36. Gene Cards, the Human Gene Database, OPN4 Gene. Available online: http://www.genecards.org/cgi-bin/carddisp.pl?gene= OPN (accessed on 4 March 2020).

37. Roecklein, K.A.; Wong, P.M.; Franzen, P.L.; Hasler, B.P.; Wood-Vasey, W.M.; Nimgaonkar, V.L.; Miller, M.A.; Kepreos, K.M.; Ferrell, R.E.; Manuck, S.B. Melanopsin gene variations interact with season to predict sleep onset and chronotype. Chrono Int. 2012, 29, 1036-1047. [CrossRef] [PubMed] 